\title{
BMJ Open Turnover intention among primary health workers in China: a systematic review and meta-analysis
}

\author{
Rongxin He (D) , ${ }^{1,2}$ Jinlin Liu (D) , , Wei-Hong Zhang, ${ }^{3}$ Bin Zhu, ${ }^{1,2}$ Ning Zhang, ${ }^{1,2}$ \\ Ying $\mathrm{Mao}^{1,2}$
}

To cite: He R, Liu J, Zhang W$\mathrm{H}$, et al. Turnover intention among primary health workers in China: a systematic review and meta-analysis. BMJ Open 2020;10:e037117. doi:10.1136/ bmjopen-2020-037117

- Prepublication history and additional material for this paper is available online. To view these files, please visit the journal online (http://dx.doi.org/10. 1136/bmjopen-2020-037117).

Received 19 January 2020 Revised 09 July 2020 Accepted 13 August 2020
Check for updates

(C) Author(s) (or their employer(s)) 2020. Re-use permitted under CC BY-NC. No commercial re-use. See rights and permissions. Published by BMJ.

${ }^{1}$ Department of Social Security, School of Public Policy and Administration, Xi'an Jiaotong University, Xi'an, Shaanxi, China ${ }^{2}$ Research Center for the Belt and Road Health Policy and Health Technology Assessment, Xi'an Jiaotong University, Xi'an, China

${ }^{3}$ International Centre for

Reproductive Health,

Department of Public Health and Primary Care, Faculty of

Medicine and Health Sciences, Ghent University, Gent, Belgium

Correspondence to Professor Ying Mao; mao_ying@mail.xjtu.edu.cn

\section{ABSTRACT}

Objectives To analyse the prevalence and determinants of turnover intention (TI) among primary health workers (PHWs) in China to provide evidence for improving retention measures.

Design Systemic review and meta-analysis.

Data sources Four English-language databases (PubMed, EMBASE, Cochrane Library, PsycINF0) and three Chinese databases (CNKI, CSPD, CBM) were searched up to October 2019

Eligibility criteria Eligible studies were observational or descriptive studies conducted in mainland China. The prevalence of $\mathrm{TI}$ among health workers and related factors had to be explicitly reported in each included study.

Data extraction and synthesis Data were extracted by one author and reviewed independently by two other authors. For each factor analysed by a meta-analysis, the factor was required to be the same across different studies, and at least three studies had to include it. The quality of studies was assessed using the NewcastleOttawa Scale and heterogeneity was evaluated using the $I^{2}$ statistic.

Results We identified 16 cross-sectional studies investigating a total of 37672 PHWs. The prevalence of $\mathrm{TI}$ was $30.4 \%$. Subgroup analysis revealed that the highest prevalence was observed in the community primary healthcare institutions and the eastern provinces of China. Meta-analyses indicated that 21 factors were significantly associated with $\mathrm{TI}$, including demographic factors (gender, age, education, marital status), job characteristic factors (title, work seniority, remuneration, social status, organisational affiliation, work stress) and job satisfaction factors (learning and training opportunity, interpersonal relationship, work condition and environment, and so on). Conclusion This study highlights the problem of $\mathrm{TI}$ among PHWs in China. Efforts should be made to improve conditions in both work-related areas and areas outside of work. Policymakers should continue to improve reward systems, the construction of infrastructure and promotion systems, and pay more attention to PHWs' lives outside of work and meet their living needs.

\section{INTRODUCTION}

Primary healthcare (PHC) addresses the majority of a person's health needs throughout their lifetime. The Declaration of Astana declared that strengthening PHC

\section{Strengths and limitations of this study}

This systematic review provides supplemental evidence from China to global studies on the turnover intention (TI) of primary health workers (PHWs).

- Meta-analysis and narrative analysis are performed to identify the risk factors for TI among PHWs.

- Due to the limitation and shortage of the current studies, significant heterogeneity among the individual studies is evident after the subgroup analysis and part of the meta-analysis are performed.

is the most inclusive, effective and efficient approach to enhance people's physical and mental health and social well-being. ${ }^{1}$ Primary health workers (PHWs) are direct providers of PHC, and their quantity directly determines the quantity, quality and outcomes of PHC. ${ }^{2}$ These services should be provided with compassion, respect and dignity by health professionals who are well trained, skilled, motivated and committed. ${ }^{1}$ However, primary health institutions are facing significant labour shortages worldwide, ${ }^{3}$ not only in lowincome and middle-income countries ${ }^{245}$ but also in developed countries. ${ }^{67}$ In China, PHC services including basic medical and public health services, are provided by community health centres and stations in urban areas and by township health centres and village clinics in rural areas. ${ }^{8}$ These four types of PHC institutions constitute the essential part of China's three-tertiary healthcare delivery network. PHWs working inside include doctors, nurses, public health workers and administrative staff, most of them have to play multiple roles. Currently, PHC institutions are all facing the problem of staff turnover, aggravating the shortage of the health workforce, ${ }^{9}$ which has become one of the significant obstacles to strengthening China's primary healthcare services. ${ }^{10}$

Turnover, a behaviour of actually leaving, was an important value in human resources 
management and maintenance of the current workforce. ${ }^{11}$ Turnover intention (TI) is defined as the probability that an employee will leave his or her job within a specific period $^{12}$; TI is considered to be one of the best predictors of turnover behaviour. ${ }^{13-16}$ Previous studies have explored the factors that influence the TIs of PHWs. A variety of factors have been identified, such as demographic factors, ${ }^{717-22}$ job satisfaction, ${ }^{18}{ }^{20} 22-25$ work stress, ${ }^{131825}$ burnout, ${ }^{23} 26$ quality of work-life, ${ }^{21}$ interpersonal communication ${ }^{27}$ and violence from patients. ${ }^{28}$ While these factors have been definitely linked with TI, some researchers have focused on factors outside of work. Han and Humphreys ${ }^{29}$ found that key factors of community integration influence overseas-trained doctors' decision to stay in or leave a rural community in Australia; Stewart et $a l^{17}$ reported that community satisfaction is a crucial predictor of intent to leave among rural and remote registered nurses in Canada; and Chao et al and $\mathrm{Lu}$ et $a l^{1213}$ demonstrated that there is a significant correlation between work-family conflict and the TI of PHWs in Taiwan and Guangdong.

In China, many empirical studies have been conducted. However, there is no consistent conclusion on the prevalence and determinates of TI among PHWs in China. Furthermore, most of them were published in Chinese, only a few studies on TI and risk factors for PHWs have been published in international journals, and no related systematic reviews have been found in either Chinese or English. Therefore, this study aims to examine the prevalence of TI and identify the related factors among PHWs in China by conducting a systemic review and meta-analysis.

\section{METHOD}

\section{Literature search}

This systematic review and meta-analysis were performed following the Preferred Reporting Items for Systematic Reviews and Meta-Analyses guidelines. ${ }^{30} 31$ A systematic search of the literature was conducted up to October 2019 using four English-language databases (PubMed, EMBASE, Cochrane Library, PsycINFO) and three Chinese databases (CNKI, CSPD and CBM). No limits were applied for language and publication dates of coverage. The search strategy was based on a combination of "(Turnover Intention, or Departure Intention, or Demission Intention, or Leave Intention, or intent to leave), AND (Primary, Community, Rural, Countryside, District, Basic, Fundamental or Grassroots), AND (Health worker, Health officer, Health Manpower, Health Personnel, Medical Personnel, Medical worker, Medical staff, Doctor, Physician, or Nurse) and (China, or Chinese)". References of the retrieved studies were also checked and screened. The full search strategy can be found in the online supplemental table S1.

\section{Study eligibility}

Eligible studies were published studies that reported the prevalence and related determinants of TI among
Chinese PHWs. The eligibility criteria included the following: (1) types of studies: original cross-sectional studies (those presenting non-original data, such as reviews, editorials, opinion papers or letters to the editor, were excluded); (2) types of participants: Chinese PHWs; (3) types of risk factor: demographic factors, job characteristic factors and job satisfaction factors; and (4) types of outcome measures: the prevalence of TI and related factors reported in the study.

Eligibility assessment was conducted to screen the titles, abstracts and full texts of the identified studies by two reviewers independently. Disagreements on which studies should be included or excluded were resolved by full group consensus.

\section{Data extraction}

A piloted form referred to the Cochrane Effective Practice and Organization of Care Review Group data collection checklist, ${ }^{32}$ was used to extract relevant data from the included full-text studies. The following data were extracted: author, publication year, location where the study was carried out, participants, sample size, number of cases, assessment tools, prevalence of TI and related factors. Data extraction was conducted by one author and reviewed independently by two other authors, with disagreements resolved by discussion until consensus was reached. The inter-rater reliability for title screening between two authors was $96.15 \%$, and for abstract screening was $94.74 \%$. The full inter-rater reliability result can be found in the online supplemental table S2.

\section{Quality assessment}

The quality of studies was assessed using a modified Newcastle-Ottawa Scale, ${ }^{33}$ as recommended by the Cochrane Collaboration. ${ }^{34}$ Studies received scores based on the design-specific sources of bias, methods for selecting participants, exposure measures, outcome variables and methods to control confounders. ${ }^{35}$ The total score was 7 points, and all the included studies were grouped according to their scores, which were categorised as good (6-7), moderate (3-5) and poor (1-2). Specifically, a study with a sample size of less than 1000 was regarded as having poor representativeness of the sample (score $=0$, otherwise $=1$ ); a cross-sectional study with a response rate lower than $80 \%$ or without reporting a response rate was considered a poor-quality study ( score $=0$, otherwise $=1$ ). Meanwhile, if statistical methods used in the study were exact, we considered statistical test to be appropriate (score $=1$, otherwise $=0$ ), even if there was no further multivariate analysis. Three authors independently scored all included studied, with disagreements resolved by discussion until consensus was reached.

\section{Data synthesis and statistical analysis}

The primary outcome in this review was the difference in the prevalence or relative risk of TI among different groups. The prevalence of TI was estimated as the total number of TI cases divided by the total number of PHWs 
participating in the study. It was assessed via single-arm analysis. We compared the difference in TI between PHWs from different regions and institutions by subgroup analyses. The secondary outcome of this study was the association between factors and TI among PHWs in the form of the OR. Each factor analysed by a meta-analysis, required related variables in the questionnaire to be the same in different studies, which meant that it was feasible to merge the factor into two groups; meanwhile, at least three studies related to each factor had to be included in the meta-analysis. When the meta-analysis was performed, the significance of the pooled OR was determined by the Z-test. Heterogeneity was estimated by the $Q$ statistic and evaluated using the $\mathrm{I}^{2}$ statistic. ${ }^{36}$ A fixed-effect model was used to compute the summary risk estimate if there was no heterogeneity among the studies, whereas a randomeffects model was used when heterogeneity existed $\left(\mathrm{I}^{2}\right.$ $\geq 50 \%) .{ }^{37}$ Publication bias was evaluated using Egger's test. All statistical analyses were performed using Stata V.13.0 and RevMan V.5.3. A two-tailed p value of $<0.05$ was considered to be statistically significant. We referred to the Meta-analysis of Observational Studies in Epidemiology guideline. ${ }^{38}$ If it was infeasible to make a quantitative synthesis and conduct a meta-analysis, a narrative approach and descriptive statistics were used by grouping studies that reported the same factors, and to compare their associations with the TI of PHWs.

\section{Patient and public involvement}

Patients and the public were not involved in this study.

\section{RESULTS}

A total of 455 records were identified through our initial database search (PubMed: 13, Embase: 14, Coherence:
6, PsycINFO: 0, CNKI: 124, WAN FANG Data: 270, CBM: 28). After duplicate records were removed, 208 records were screened based on title and abstract. Eighty-seven articles were included in the full-text review. Among these, 63 articles were eliminated due to a lack of original data. Three articles were eliminated due to the inappropriate study designs. Five articles were excluded because of missing data on risk factors for TI. Ultimately, 16 studies were included in this study. No additional studies were obtained after the references of all 16 retrieved articles were checked. The study selection process is shown in figure 1 .

\section{STUDY CHARACTERISTICS}

Table 1 presents the main characteristics of all 16 studies. These studies were all cross-sectional and performed in 24 provinces of China between 2011 and 2019. The selected studies included 37672 participants, with a median sample size of 1073 (range 127-16 157). Five studies were conducted in eastern China, ${ }^{39-43}$ four in central provinces $^{19}{ }^{44-46}$ and four in the western region. ${ }^{18}{ }^{47-49}$ Four studies were conducted in urban areas, ${ }^{39} 404450$ eight in rural areas ${ }^{18} 194246-4951$ and four in both areas. ${ }^{41} 434552$ Thirteen studies used a dichotomous question to measure TI (Do you want to leave your job? Yes/No) and three studies used scales. All studies reported the prevalence and related factors of TI among PHWs.

Forty-seven factors were extracted from 16 included studies (online supplemental table S3). It included three groups: 7 demographic factors, 22 job characteristic factors and 18 job satisfaction factors. The average quality score of the 16 included studies was 5.25 of 7 points, indicating a moderate research

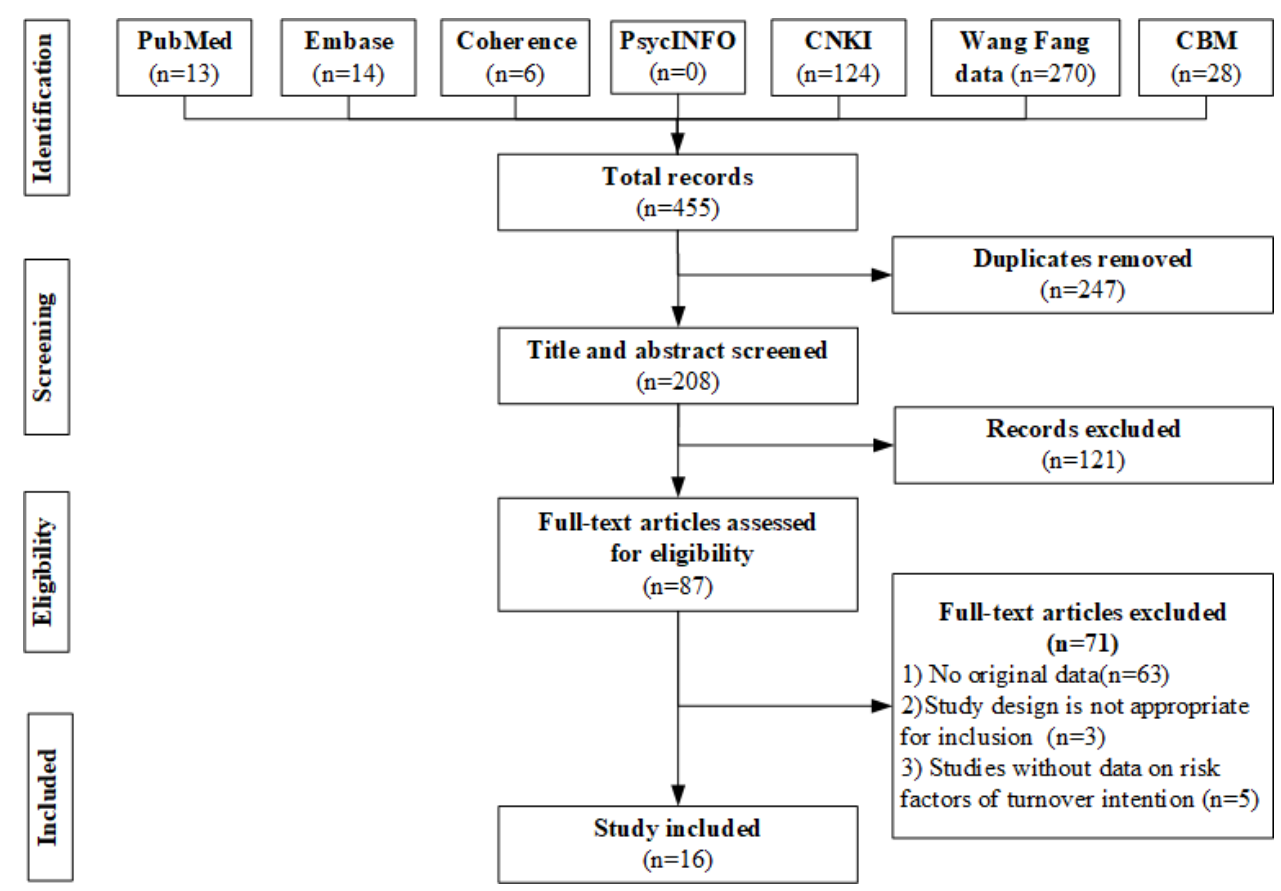

Figure 1 Flow diagram of the study selection. 
Table 1 Characteristics of 16 included studies

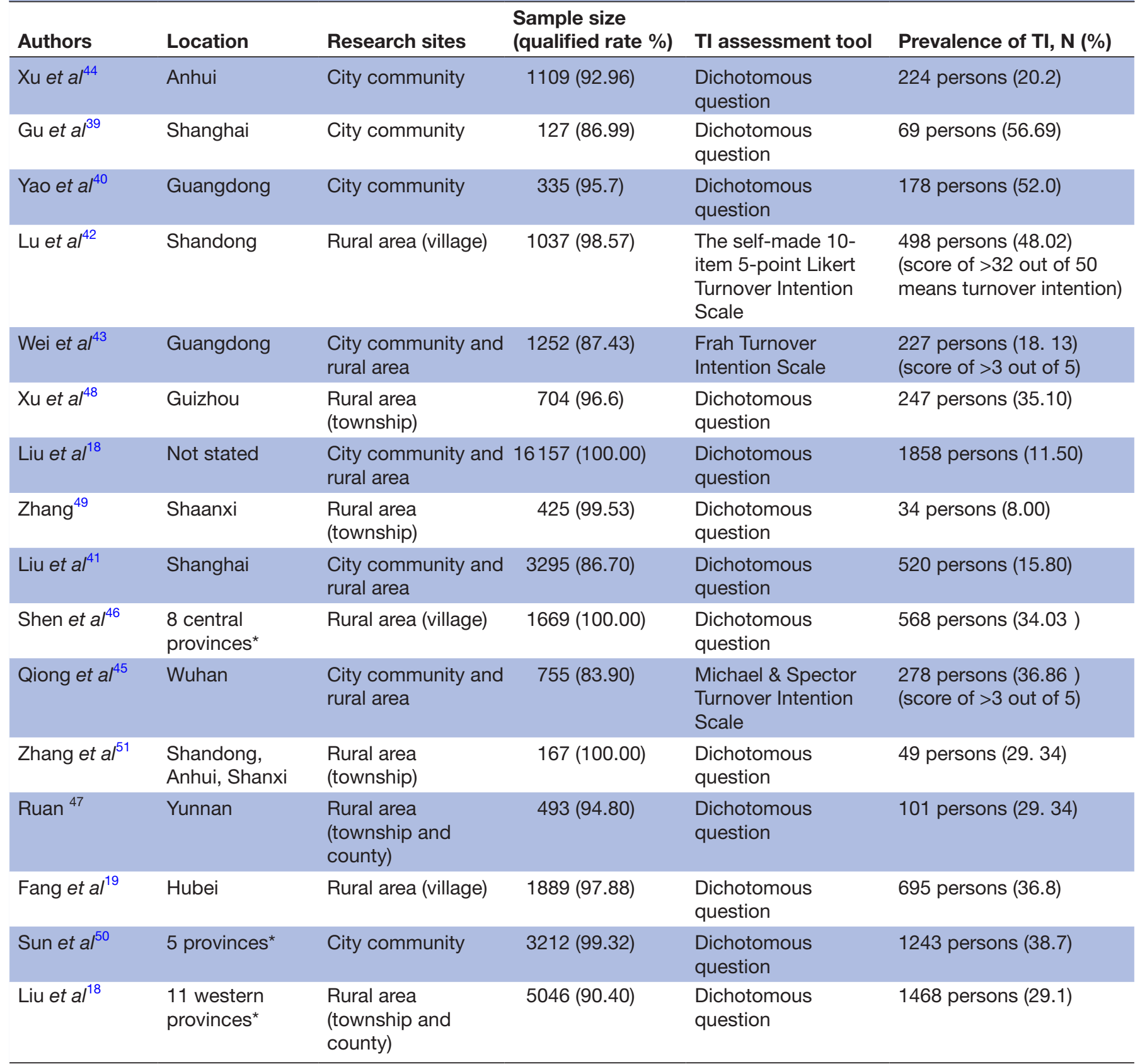

*Eight provinces: Shanxi, Jilin, Heilongjiang, Anhui, Jiangxi, Henan, Hubei and Hunan; 5 provinces: Zhejiang, Guangdong, Guizhou, Hebei and Hubei; 11 provinces: Gansu, Guangxi, Guizhou, Inner Mongolia, Ningxia, Qinghai, Shaanxi, Sichuan, Tibet, Xinjiang and Yunnan.

TI, turnover intention.

quality, according to the modified Newcastle-Ottawa Scale (online supplemental table S4). All studies were of the medium and high quality.

\section{Prevalence of TI among PHWs}

Table 2 shows the prevalence of TI among PHWs in China. The pooled prevalence was $30.4 \%$. The highest prevalence was $54.3 \%$ reported by $\mathrm{Gu}$ et $a l,{ }^{39}$ whereas Zhang reported the lowest prevalence of $8.0 \% .{ }^{49}$ The subgroup analysis by region showed that the highest prevalence was observed in the eastern China (37.6\%), followed by central regions (31.9\%) and western regions $(23.2 \%)$. According to work setting, the highest prevalence occurred among PHWs working in the community, followed by rural PHWs working in townships and villages. With respect to sample size, the prevalence of TI was higher in studies having a sample size $<1037(35.5 \%)$ than in those with a sample size $\geq 1037$ $(25.5 \%)$. High heterogeneity was observed across the included studies due to the inconsistent research sites, regions and objects. 
Table 2 Prevalence of turnover intention among PHWs in China

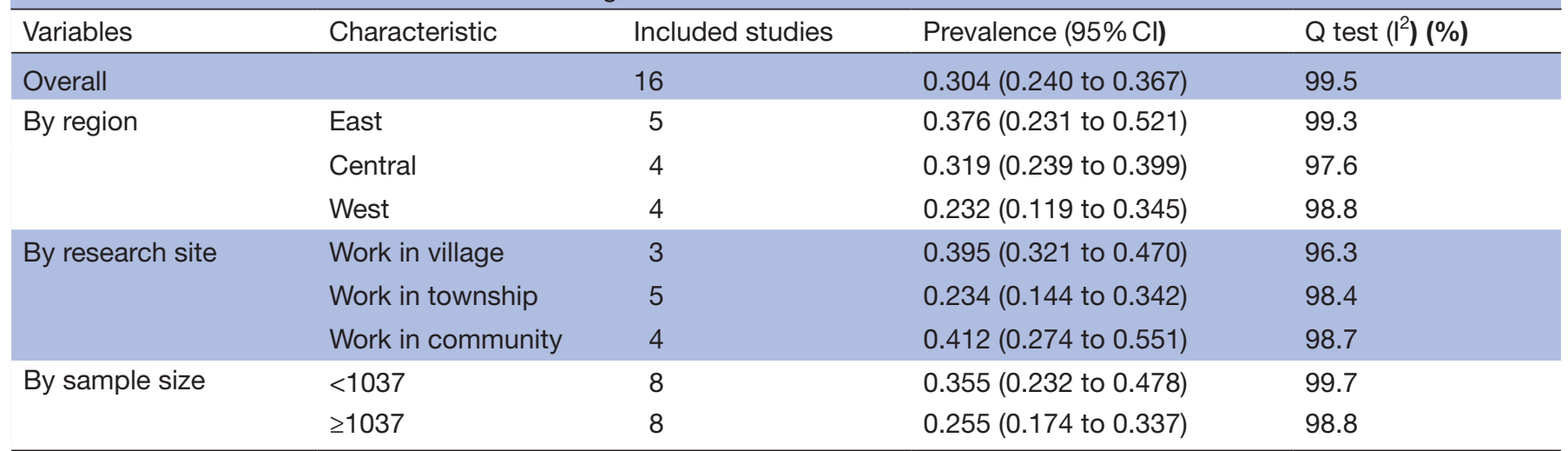

PHWs, primary health workers.

\section{Factors related to $\mathrm{TI}$ among PHWs}

All studies reported demographic factors or job characteristic factors and determined their associations with the TI of PHWs. Moreover, six studies explored the effects of job satisfaction factors, ${ }^{19} 4245-48$ and 19 factors were feasible for inclusion in the meta-analyses. Egger's linear regression tests on a natural logarithm scale of OR found no evidence of publication bias for the studies included in meta-analyses (online supplemental table S5).

\section{Demographic factors and TI}

The meta-analysis of demographic factors was based on 15 cross-sectional studies (figure 2). Gender (male vs female, OR: 1.23), ${ }^{18} 1940-485052$ age (younger vs older, OR: 1.47$)^{40414448-5052}$ and marriage status (unmarried vs married, OR: 1.16) ${ }^{184143-454748}$ were significantly associated with TI in PHWs, which showed that the PHWs with higher risks of TI were men, were younger, had a higher education, were unmarried and worked in the remote region. But education (low-education vs high-education, OR: 0.78) $18194143-4648-50$ was not statistically significant.

\section{Job characteristic factors and TI}

Job characteristic factors were examined in nine studies (figure 3). Job title (low-title vs high-title, OR: 1.11), ${ }^{18} 404143-464850$ work seniority (short vs long, OR: $1.17),{ }^{40} 464950$ organisational affiliation (strength vs others, OR: 0.85$)^{414452}$ and work stress (high vs low, OR: $3.14)^{4345474852}$ were significantly associated with the TI of PHWs, which presented that the PHWs with higher risks of TI were those with shorter work seniority, higher work stress and longer working hours. However, occupation (doctor vs nurse, OR: 1.05) 404143450 was not statistically significant.

\section{Job satisfaction factors and TI}

Six studies explored the association between job satisfaction factors and TI (figure 4). Overall job satisfaction (satisfied vs dissatisfied, OR: 0.15), ${ }^{39} 4245$ promotion and individual development space (satisfied vs dissatisfied, OR: 0.19), ${ }^{19} 4748$ interpersonal relationships (satisfied vs dissatisfied, OR: 0.20), ${ }^{19} 4748$ keep busy and fulfilling (satisfied vs dissatisfied, OR: 0.39), ${ }^{19424748}$ sense of accomplishment (satisfied vs dissatisfied, OR:0.16), ${ }^{1942} 47$ income satisfaction (satisfied vs dissatisfied, OR: 0.33), $194246-48$ work condition and environment (satisfied vs dissatisfied, OR: 0.19), ${ }^{19424748}$ level of attention by leaders (satisfied vs dissatisfied, OR: 0.20), ${ }^{19} 4748$ the competence of my manager in making decisions (satisfied vs dissatisfied, OR: 0.18), ${ }^{19} 4748$ and motivation and salary system (satisfied vs dissatisfied, OR: 0.21) ${ }^{4547}$ were significantly associated with the TI of PHWs. The results showed that PHWs who were dissatisfied with their job had significantly higher risks of $\mathrm{TI}$.

The remaining 28 exposures were analysed for their associations with the TI of PHWs under a narrative approach. In the demographic factors group, PHWs who work in remote regions ${ }^{41}$ and who have lower remuneration $^{184752}$ and social status ${ }^{42} 4748$ were found to have significantly higher risks of TI. No significant associations were found between TI and the nation. ${ }^{46} 47$ In addition, the associations between TI and major in clinical medicine are inconclusive. ${ }^{46} 47$

Among job characteristic factors, seven were significantly associated with high risks of TI, including lower individual remuneration levels at the local level, ${ }^{19} 42$ more severe emotional exhaustion, ${ }^{42}{ }^{46}$ more severe flattening of affect, ${ }^{46}$ more participation in public health service, ${ }^{51}$ longer working hours, ${ }^{47}$ no career planning ${ }^{47}$ and lack of insurance. ${ }^{46}$ No significant associations were found between TI and qualified to practice, ${ }^{19}$ re-employ after retirement, ${ }^{48}$ turnover experience, ${ }^{47}$ career identity, ${ }^{47}$ influence on family life,${ }^{50}$ patient trust. ${ }^{47}$ In addition, the associations between TI and living condition are inconclusive. $^{47} 48$

Regarding job satisfaction factors, PHWs who are unsatisfied with work stability, ${ }^{19} 47$ the chance to try their own methods of performing their job, ${ }^{19}$ the chance to do something that makes use of their abilities, ${ }^{19}{ }^{47}$ work support, ${ }^{42}$ policies practice ${ }^{19} 4547$ and income fairness ${ }^{45} 47$ were found to have significantly high risks of TI. However, no statistically significant associations were found between TI and the satisfaction with the 


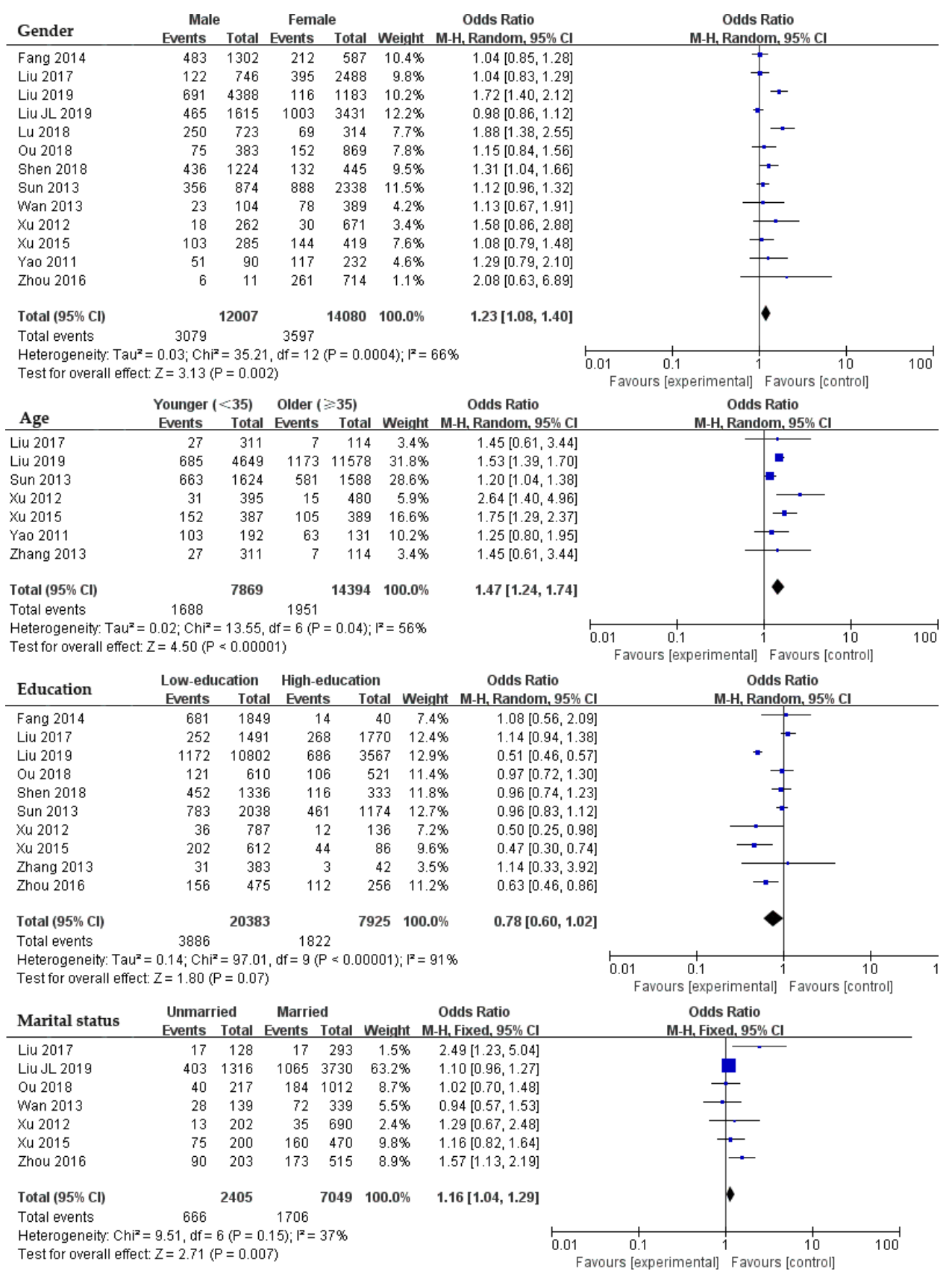

Figure 2 Forest plots of demographic factors.

scientific research atmosphere or learning and training opportunity. ${ }^{46-48}$

\section{DISCUSSION}

\section{Principal findings}

This systematic review presents an overall prevalence of TI $(30.4 \%)$ among Chinese PHWs which indicated that three of ten PHWs have TI. However, this finding is almost two times higher than that of some high-income countries. A study conducted in England showed that only $11.8 \%$ of primary care doctors had high TI. ${ }^{53} \mathrm{~A}$ survey including 23159 nurses from 10 European countries showed that $9 \%$ of all these nurses intended to leave their profession, varying from $5 \%$ to $17 \%$ among countries ${ }^{54}$
Another survey performed among 2263 physicians in America reported that $18.4 \%$ of them intended to leave their practice. ${ }^{55}$ A study conducted in Canada reported that $17.2 \%$ of registered nurses intended to leave their current nursing position. ${ }^{17}$ Meanwhile, the prevalence of TI was lower than in some low-income and middleincome countries, such as Ghana, ${ }^{20}$ Iraq,${ }^{56}$ South Africa ${ }^{22}$ and the Philippines. ${ }^{57}$

The subgroup analysis indicated the variation in the prevalence of TI among regions. The possible explanations for this variation might be the difference in the level of social and economic development and the workplace. In East China, there are more urban hospitals than in other regions, providing more jobs, higher pay and a 


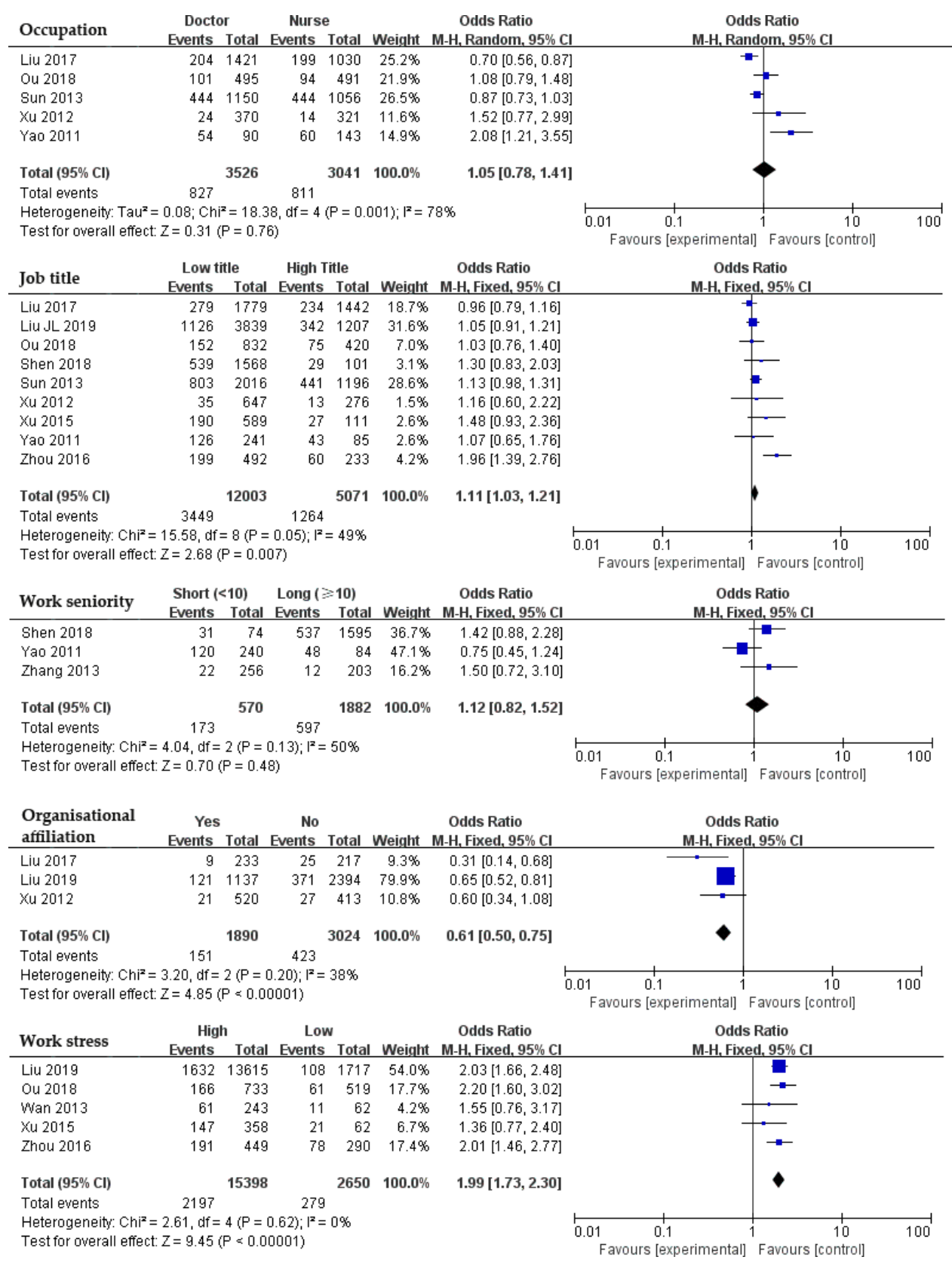

Figure 3 Forest plots of job characteristic factors.

better work environment. It attracts many PHWs to move away from primary care practice. ${ }^{58}$ As rural PHWs, they usually settled down in rural areas, lacking access to urban hospitals compared with peers in the urban community.

This study extracted a broad scope of 47 related factors and determined their associations with the TI of PHWs, identifying a total of 31 demographic, job characteristic and job satisfaction risk factors.

Five demographic risk factors were determined to have significant associations with the TI of PHWs, which showed that the PHWs who were men, were younger, had a higher education, were unmarried and worked in the remote region with high risks of TI. Some of these findings are in line with studies performed in South Africa, the Philippines, Canada, Saudi Arabia, Ghana and the Netherlands. ${ }^{17} 20-222557$ However, Bonenberger et $a l^{20}$ and Labrague et a $\tilde{p}^{7}$ showed that the association between gender and the TI of PHWs was not statistically significant. It can be concluded that different types of PHWs have unique characteristics of TI. Accordingly, we can sum up the high-risk population among PHWs. For example, the TIs of an unmarried young practitioner who received full medical training could be expected to be higher than a married older practitioner with limited training. The policymakers and medical institutions managers should formulate or adjust retention measures based on these characteristics.

According to job characteristic factors, we concluded that PHWs who had shorter work seniority, higher work stress and longer working hours had significantly higher risks of TI. All of these findings are consistent with prior studies. Nevertheless, some 


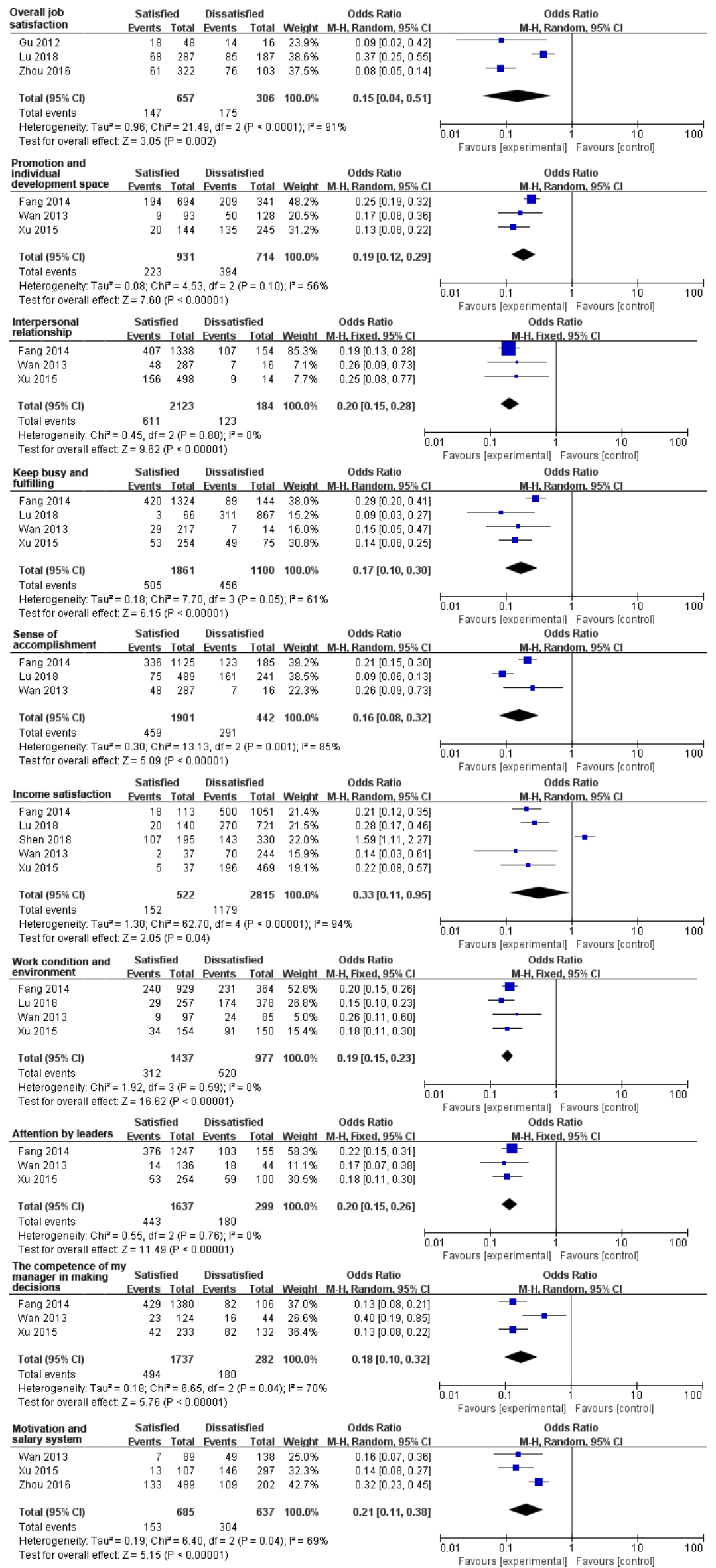

Figure 4 Forest plots of job satisfaction factors. 
findings are inconsistent with prior studies. Remuneration was found to be statistically significant in the review, which is consistent with Almalki et $a l^{21}$ but Labrague et a $\tilde{l}^{7}$ reported an insignificant association between remuneration and TI. Occupation and level of the medical institution were not significantly associated with TI in the review, in accordance with Warmelink et $a l^{25}$ and Labrague et $a l .{ }^{57}$ However, some studies reported the opposite results. ${ }^{172}$ In addition, seven factors identified in the review were never or rarely reported in other countries, including title, social status, participation in public health service, insurance, career planning, emotional exhaustion or flattening of affect and authorised personnel, which were found to have significant associations with a high risk of TI among PHWs in China. Among these factors, 'emotional exhaustion' and 'flattening of affect' are measures of mental health status. In recent years, the mental health status of the health workforce has deteriorated due to increasing work stress and violence. ${ }^{5960}$ Some studies also found that mental health has significant associations with job satisfaction and job burnout. ${ }^{182661}$ In the context of COVID-19, all PHWs have been mobilised to fight the epidemic, which will undoubtedly have a negative impact on their mental health status. ${ }^{62} 63$ The risk of TIs caused by mental health problems cannot be ignored.

There is a significant inverse association between job satisfaction and TI. In this review, we found that low overall job satisfaction reported significantly higher risks of TI among PHWs, which is in line with Bonenberger $e t$ $a l,{ }^{20}$ Warmelink $e t a l^{25}$ and Delobelle $e t a l .{ }^{22}$ Furthermore, most of the job satisfaction factors are also significantly associated with the TI of PHWs. However, these specific job satisfaction factors have rarely been reported in previous studies.

Notably, compared with previous studies focused on the family factors, ${ }^{17}{ }^{21}$ our study did not find relevant evidence on family factors in China such as: community satisfaction, numbers of dependent family members or family commitments.

\section{Limitations and strengths}

To our knowledge, this is the first systematic review (including meta-analysis) to determine potential risk factors for TI among Chinese PHWs. Our findings present an overview of the current evidence from mainland China. One strength of this review is that it estimated the prevalence of TI among Chinese PHWs based on a large sample size with a total of 16 cross-sectional studies and 37672 participants. Another strength is that it determines the associations of a broad scope of potential risk factors. Limitations exist in this systematic review. Significant heterogeneity among the individual studies was found when the subgroup analysis and the part of meta-analysis were performed. The main reason is the heterogeneity between different studies in research region and research site. Due to the limitation and shortage of the current studies, it is hard to conduct a further study.

\section{Literature gaps}

Therefore, it can be concluded that there are many facets of the TIs among PHWs that need to be explored. First, the differences in TI by occupation within the different regions or institutions need to be explored. Second, there is insufficient research on the interaction effects of demographics and other factors. More research is needed to better represent and understand how two or more determinants work together to impact the TIs of PHWs. Third, the impact of family factors on TIs requires more attention. Last but not least, the relationship between public health services and the TIs of PHWs in the context of the COVID-19 is a worthy research issue.

\section{CONCLUSION}

The analysis highlights the problem of TIs among PHWs in China. There is a significant association between demographic factors, job characteristic factors, job satisfaction factors and TIs. Policymakers should take into account all aspects of human needs that influence PHWs' intentions to stay. As illustrated by the Global Strategy on Human Resources for Health, it is particularly important to find pragmatic solutions to overcome deeply entrenched rigidities in public sector rules and practices that hinder the adoption of adequate reward systems, working conditions and career structures for health workers, with appropriate levels of flexibility and autonomy. ${ }^{64}$ Therefore, efforts can be made to improve factors both at work and outside of work. In terms of work factors, policymakers should continue to improve reward systems, the construction of infrastructure and promotion systems. Outside of work, authorities should pay more attention to PHWs' lives and meet their living needs to increase their willingness to work and live in communities, towns and villages. We also suggest that particular attention be given to PHWs working in the community or the eastern region of China to reduce their TIs by implementing evidencebased health workforce policies.

Contributors $\mathrm{RH}$ and $\mathrm{YM}$ conceived this research project. $\mathrm{JL}$ and $\mathrm{RH}$ developed the search strategy and RH searched the databases. JL, BZ, NZ and RH selected the studies. RH designed and executed the analyses, interpreted the findings, wrote the first draft, revised subsequent drafts, and prepared the manuscript. YM and WHZ revised drafts of the manuscript.

Funding This research was funded by the Major Project of National Social Science Fund of China: Research on big health putting prevention first and construction of healthy China (grant number 17ZDA079).

Competing interests None declared.

Patient and public involvement Patients and/or the public were not involved in the design, or conduct, or reporting, or dissemination plans of this research.

Patient consent for publication Not required.

Provenance and peer review Not commissioned; externally peer reviewed.

Data availability statement All data relevant to the study are included in the article or uploaded as supplemental information. No additional data are available from the authors. 
Open access This is an open access article distributed in accordance with the Creative Commons Attribution Non Commercial (CC BY-NC 4.0) license, which permits others to distribute, remix, adapt, build upon this work non-commercially, and license their derivative works on different terms, provided the original work is properly cited, appropriate credit is given, any changes made indicated, and the use is non-commercial. See: http://creativecommons.org/licenses/by-nc/4.0/.

\section{ORCID iDs}

Rongxin He http://orcid.org/0000-0002-9036-3416

Jinlin Liu http://orcid.org/0000-0002-7655-8532

\section{REFERENCES}

1 WHO, UNICEF, HIS, SDS. Declaration of Astana. Global Conference on Primary Health Care, 2018.

2 Espinosa-González AB, Normand C. Challenges in the implementation of primary health care reforms: a qualitative analysis of stakeholders' views in turkey. BMJ Open 2019;9:e027492.

3 Truth U. GHWA-a_universal_truth_report.

4 Nkomazana O, Mash R, Shaibu S, et al. Stakeholders' perceptions on shortage of healthcare workers in primary healthcare in Botswana: Focus group discussions. PLoS One 2015;10:e0135846:1-15.

5 Aluko JO, Anthea R, Marie Modeste RR. Manpower capacity and reasons for staff shortage in primary health care maternity centres in Nigeria: a mixed-methods study. BMC Health Serv Res 2019;19:1-15.

6 MacLean L, Hassmiller S, Shaffer F, et al. Scale, causes, and implications of the primary care nursing shortage. Annu Rev Public Health 2014;35:443-57.

7 Gan Y, Gong Y, Chen Y, et al. Turnover intention and related factors among general practitioners in Hubei, China: a cross-sectional study. BMC Fam Pract 2018;19:1-9.

$8 \mathrm{Li} \mathrm{H}$, Yuan B, Wang D, et al. Motivating factors on performance of primary care workers in China: a systematic review and metaanalysis. BMJ Open 2019;9:e028619.

9 Wu J, Yang Y. Inequality trends in the demographic and geographic distribution of health care professionals in China: data from 2002 to 2016. Int J Health Plann Manage 2019;34:e487-508

10 WCM Y, Hsiao WC, Chen W, et al. Early appraisal of China's huge and complex health-care reforms. The Lancet 2012;379:833-42.

11 Nancarrow S, Bradbury J, Pit SW, et al. Intention to stay and intention to leave: are they two sides of the same coin? A crosssectional structural equation modelling study among health and social care workers. J Occup Health 2014;56:292-300.

12 Lu Y, Hu X-M, Huang X-L, et al. The relationship between job satisfaction, work stress, work-family conflict, and turnover intention among physicians in Guangdong, China: a cross-sectional study. BMJ Open 2017;7:e014894.

13 Chao M-C, Jou R-C, Liao C-C, et al. Workplace stress, job satisfaction, job performance, and turnover intention of health care workers in rural Taiwan. Asia Pac J Public Health 2015;27:NP1827-36.

14 Holtom BC, O'Neill BS. Job embeddedness: a theoretical foundation for developing a comprehensive nurse retention plan. J Nurs Adm 2004;34:216-27.

15 Yamaguchi $\mathrm{Y}$, Inoue $\mathrm{T}$, Harada $\mathrm{H}$, et al. Job control, work-family balance and nurses' intention to leave their profession and organization: a comparative cross-sectional survey. Int J Nurs Stud 2016;64:52-62.

16 Battistelli A, Portoghese I, Galletta M, et al. Beyond the tradition: test of an integrative conceptual model on nurse turnover. Int Nurs Rev 2013;60:103-11.

17 Stewart NJ, D'Arcy C, Kosteniuk J, et al. Moving on? predictors of intent to leave among rural and remote rns in Canada. $J$ Rural Health 2011;27:103-13.

18 Liu J, Zhu B, Wu J, et al. Job satisfaction, work stress, and turnover intentions among rural health workers: a cross-sectional study in 11 Western provinces of China. BMC Fam Pract 2019;20:1-11.

19 Fang $\mathrm{P}$, Liu X, Huang L, et al. Factors that influence the turnover intention of Chinese village doctors based on the investigation results of Xiangyang City in Hubei Province. Int J Equity Health 2014;13:1-9.

20 Bonenberger M, Aikins M, Akweongo P, et al. The effects of health worker motivation and job satisfaction on turnover intention in Ghana: a cross-sectional study. Hum Resour Health 2014;12:1-12.

21 Almalki MJ, FitzGerald G, Clark M. The relationship between quality of work life and turnover intention of primary health care nurses in Saudi Arabia. BMC Health Serv Res 2012;12:314.

22 Delobelle P, Rawlinson JL, Ntuli S, et al. Job satisfaction and turnover intent of primary healthcare nurses in rural South Africa: a questionnaire survey. J Adv Nurs 2011;67:371-83.
23 Roy A, van der Weijden T, de Vries N. Relationships of work characteristics to job satisfaction, turnover intention, and burnout among doctors in the district public-private mixed health system of Bangladesh. BMC Health Serv Res 2017;17:1-11.

24 Zhang M, Yan F, Wang W, et al. Is the effect of personorganisation fit on turnover intention mediated by job satisfaction? A survey of community health workers in China. BMJ Open 2017;7:e013872:1-8

25 Warmelink JC, Wiegers TA, de Cock TP, et al. Career plans of primary care midwives in the Netherlands and their intentions to leave the current job. Hum Resour Health 2015;13:1-10.

26 Chen X, Ran L, Zhang Y, et al. Moderating role of job satisfaction on turnover intention and burnout among workers in primary care institutions: a cross-sectional study. BMC Public Health 2019;19:1-10.

27 Moreland JJ, Ewoldsen DR, Albert NM, et al. Predicting nurses turnover: the aversive effects of decreased identity, poor interpersonal communication, and learned helplessness. J Health Commun 2015;20:1155-65.

28 Eneroth M, Gustafsson Sendén M, Schenck Gustafsson K, et al. Threats or violence from patients was associated with turnover intention among foreign-born GPs - a comparison of four workplace factors associated with attitudes of wanting to quit one's job as a GP. Scand J Prim Health Care 2017;35:208-13.

29 Han G-S, Humphreys JS. Overseas-Trained doctors in Australia: community integration and their intention to stay in a rural community. Aust J Rural Health 2005;13:236-41.

30 Liberati A, Altman DG, Tetzlaff J, et al. The PRISMA statement for reporting systematic reviews and meta-analyses of studies that evaluate health care interventions: explanation and elaboration. PLoS Med 2009;6:e1000100.

31 Moher D, Liberati A, Tetzlaff J, et al. Preferred reporting items for systematic reviews and meta-analyses: the PRISMA statement. PLoS Med 2009;6:e1000097.

32 EPOC. Cochrane Effective Practice and Organisation of Care Review Group (EPOC) - Data Collection Checklist. Epoc, 2008.

33 Modesti PA. Cross Sectional Study Newcastle - Ottawa Quality Assessment Scale. PLOS ONE 2016;11:1-2.

34 Higgins J, Green S. Chapter 22: overview of reviews. In: Cochrane Handbook for systematic reviews of interventions. Cochrane database of systematic reviews, 2008: 187-235.

35 Allen L, Williams J, Townsend N, et al. Socioeconomic status and non-communicable disease behavioural risk factors in low-income and lower-middle-income countries: a systematic review. Lancet Glob Health 2017;5:e277-89.

36 Higgins JPT, Thompson SG, Deeks JJ, et al. Measuring inconsistency in meta-analyses. BMJ 2003;327:557-60.

37 Nikolakopoulou A, Mavridis D, Salanti G. How to interpret metaanalysis models: fixed effect and random effects meta-analyses. Evid Based Ment Health 2014;17:64.

38 Greenwood DC. Meta-Analysis of observational studies. In: Modern methods for epidemiology, 2012: 173-89.

39 Gu W-juan, Qin-kang J, Min-hong C. Empirical study on job mobility and job satisfaction of community health service center staff. Chinese J Prim Health Care 2012;26:23-6.

40 Yao W-guang, Guo-wen W, Ai-guang X, et al. Sample survey of human resources and work situation of community health services in Guangdong Province. Chinese Gen Pract 2011;14:1779-81.

41 Liu K, Li-mei J, Xu-hong Z, et al. Rural healthcare workers' turnover intention during the reform incentive polices for rural healthcare professionals implemented. Chinese Gen Pract 2017;20:2338-41.

42 Lu Y, Lei J, Li Jiang-fei BL, et al. Analyzing the stability of rural doctor team in Shandong Province in different dimensions. Health Care Manag Sci 2018:517-20.

43 Wei Ou, lin LKML. Study on fatigue status and turnover intention of primary health care workers in Guangdong. Guangdong Med J 2018;39:3081-5.

$44 \mathrm{Xu} \mathrm{Y}$, Ding Hong HZ. Study on the relationship between the subjective turnover intention of community health service personnel and demographic characteristics. Anhui Medical Journal 2012;33:481-4.

45 Qiong Z, Guan Wen-bo XJ. Correlation analysis of turnover tendency and working factors of primary nursing staff in a district of Wuhan City. J Math Med 2016;29:703-5.

46 Shen B-jie, Lin-lin H, You Li-li LY. Turnover intention and its influencing factors among village doctors in central China. Chinese Gen Pract 2018;21:4183-7.

47 Zhenzhen R. Turnover intention and correlates of health personnel at County and township levels in Yunnan. Kunming medical university, 2013. 
$48 \mathrm{Xu} \mathrm{L}$, Jun-hua W, Wen-yong $\mathrm{H}$, et al. Study of the turnover intention among rural health workers in Guizhou. Chinese J Prim Health Care 2015;29:27-30.

49 Zhang Su-mei LX. Investigation and analysis on the turnover intention of nurses in primary and secondary hospitals in shaanxi Province. Journal of Qilu Nursing 2013;19:55-7.

50 Sun Y, Luo Z, Fang P. Factors influencing the turnover intention of Chinese community health service workers based on the investigation results of five provinces. J Community Health 2013;38:1058-66.

51 Zhang $\mathrm{H}$, Wen $\mathrm{P}$, Di $\mathrm{Y}$, et al. The current situation of nursing staff and their turnover in township health centers. Chinese Journal of Health Policy 2015;8:23-8.

52 Guan-yu L. Analysis on human resource situation and influencing factors of community-level healthcare institutions, 2019.

53 Hann M, Reeves D, Sibbald B. Relationships between job satisfaction, intentions to leave family practice and actually leaving among family physicians in England. Eur J Public Health 2011;21:499-503.

54 Heinen MM, van Achterberg T, Schwendimann R, et al. Nurses' intention to leave their profession: a cross sectional observational study in 10 European countries. Int J Nurs Stud 2013;50:174-84.

55 Kao AC, Jager AJ, Koenig BA, et al. Physician perception of pay Fairness and its association with work satisfaction, intent to leave practice, and personal health. $J$ Gen Intern Med 2018;33:812-7.

56 GBD 2016 Mortality Collaborators. Global, regional, and national under-5 mortality, adult mortality, age-specific mortality, and life expectancy, 1970-2016: a systematic analysis for the global burden of disease study 2016. Lancet 2017;390:1084-150.

57 Labrague LJ, McEnroe-Petitte DM, Tsaras K, et al. Organizational commitment and turnover intention among rural nurses in the Philippines: implications for nursing management. Int J Nurs Sci 2018;5:403-8.

58 Wen $\mathrm{T}$, Zhang $\mathrm{Y}$, Wang $\mathrm{X}$, et al. Factors influencing turnover intention among primary care doctors: a cross-sectional study in Chongqing, China. Hum Resour Health 2018;16:1-11.

59 Yang SZ, Wu D, Wang N, et al. Workplace violence and its aftermath in China's health sector: implications from a crosssectional survey across three tiers of the health system. BMJ Open 2019;9:e031513:1-10.

60 Lu Y, Hu X-M, Huang X-L, et al. Job satisfaction and associated factors among healthcare staff: a cross-sectional study in Guangdong Province, China. BMJ Open 2016;6:e011388:1-9.

61 Lo D, Wu F, Chan M, et al. A systematic review of burnout among doctors in China: a cultural perspective. Asia Pac Fam Med 2018;17:1-14.

62 Gold JA. Covid-19: adverse mental health outcomes for healthcare workers. BMJ 2020;369:m1815.

63 Lai J, Ma S, Wang Y, et al. Factors associated with mental health outcomes among health care workers exposed to coronavirus disease 2019. JAMA Netw Open 2020;3:e203976.

64 Organization WH. Global strategy on human resources for health: workforce 2030. 64. WHO, 2016. 